\title{
Catalytic Enantioselective Hetero-Diels-Alder Reactions of an Azo Compound
}

\author{
Masanori Kawasaki and Hisashi Yamamoto* \\ Department of Chemistry, University of Chicago, 5735 South Ellis Avenue, Chicago, Illinois 60637
}

The hetero-Diels-Alder reaction is one of the most useful reactions in organic chemistry because multi functionalized compounds can be constructed in a single step. ${ }^{1}$ The catalytic enantioselective version of this process has attracted much attention in modern organic chemistry. We recently reported the catalytic highly enantioselective nitroso hetero-DielsAlder reaction using nitroso-pyridine as a dienophile in the presence of a chiral copper catalyst. ${ }^{2}$ Encouraged by this success, we focused on hetero-Diels-Alder reaction using a 2-azopyridine derivative since this reaction with azo compounds (azo hetero-Diels-Alder reaction) produces 1,4-diamines. ${ }^{3}$ These structural motifs are important building blocks as well as 1,4-amino alcohols. For example, these structures are found in pharmaceutically important compounds such as HIV protease inhibitors. ${ }^{4}$ Diastereoselective azo hetero-Diels-Alder reactions using a chiral auxiliary have been developed, ${ }^{5}$ however, despite several efforts toward an enantioselective version of this process, ${ }^{6}$ there are no reports of a catalytic highly enantioselective azo hetero-Diels-Alder reaction. We herein report the catalytic highly regioand enantioselective azo hetero-Diels-Alder reaction (Scheme 1).

2-Azopyridine (1) was prepared in two steps from commercially available 2-

hydrazinopyridine. ${ }^{7}$ On the basis of our previous results, we chose for initial investigations the hetero- Diels-Alder reaction of acyclic silyloxydiene 2a with $(R)$-BINAP and $\mathrm{CuPF}_{6}\left(\mathrm{CH}_{3} \mathrm{CN}\right)_{4}$ catalyst. ${ }^{2}, 8$ Unfortunately, we were unable to observe any chiral induction. Thus, several metal catalysts were surveyed ${ }^{9}$ and we found that the combination of AgOTf and $(R)$-BINAP in THF produced adduct 3a with $55 \%$ ee. Encouraged by this result, various ligands and solvents were tested (Table 1). The use of $(R)$-BINAP as a ligand and $\mathrm{CH}_{3} \mathrm{CN}$ or EtCN as a solvent gave 3a with $94 \%$ ee (Table 1, entries 5 and 6). EtCN was selected as a solvent to obtain high reproducibility. Next, the ratio of $(R)$-BINAP and AgOTf was checked since we previously had observed that three types of Ag-BINAP complex were formed in THF. 10 The 2:1 ratio of AgOTf and (R)-BINAP was found to be optimal, producing an adduct 3a with $>99 \%$ ee. It should be noted that decreased enantioselectivity was observed by chiral biphosphine ligands with narrow dihedral angles (entries 7 and 8) which are expected to generate a 1:1 complex of Ag-ligand preferentially.

Having an optimized condition in hand, the applicability of this reaction was studied for the functionalized silyloxydienes $\mathbf{2 b}-\mathbf{2} \mathbf{j} .{ }^{11}$ All of the reactions proceeded in high yields and enantio-selectivities, with complete regio- and diastereoselectivities.

The dialkyl-substituted dienes generally gave high enantio-selectivites (Table 2, entries 1, 2 and 5). Silyloxydiene $\mathbf{2 c}$ with a sterically hindered substituent afforded $\mathbf{3 c}$ with slightly decreased enantioselectivity. Lewis basic substituents such as ester, ether, protected alcohols, and protected amine (Table 2, entries 4 and 6-8) were also used in the reaction and produced highly functionalized products enantioselectively. Silyloxydiene $\mathbf{2 j}$ having 2 -furyl group gave

E-mail: yamamoto@uchicago.edu. 
an adduct $3 \mathbf{j}$ with high regio- and enantioselectivity (Table 2, entry 10). Meanwhile, the enantio-selectivity of reaction using silyloxydiene $\mathbf{2 k}$ with phenyl group was decreased dramatically (Table 2, entry 11).

The products can be cleanly converted into the corresponding diamino alcohols. For example, deprotection of TIPS group of $\mathbf{3 a}$ with TBAF/AcOH ${ }^{12}$ followed by reduction and protection of the resulting alcohol gave $\mathbf{4} \mathbf{a}$ as a single diastereomer. Removal of the pyridine ring was cleanly achieved by the known procedure, ${ }^{2 \mathrm{c}}$ ) accompanied by the conversion of $2,2,2$ trichloroethoxycarbonyl group to methoxycarbonyl group. The resulting amine was protected with trifluoroacetyl group to afford $\mathbf{5 a}$. To cleave N-N bond of 5a, 5a was treated with $\mathrm{SmI}_{2}$ to give $\mathbf{6 a}$ in $71 \%$ yield (Scheme 2). ${ }^{13}$ Thus, two amino groups are differentiated for further transformation.

The absolute and relative configurations of azo hetero-Diels-Alder adducts were assigned by $\mathrm{X}$-ray crystallographic analysis. Deprotection of Troc and TIPS groups followed by reduction afforded 7a as a single diastereomer. Subsequently, 7a was converted into 4-bromobenzoate derivative 8a which was crystallized from $\mathrm{Et}_{2} \mathrm{O}$ (Scheme 3, Supporting information).

In summary, we have developed highly regio-, diastereo-, and enantioselective azo heteroDiels-Alder reaction using 2-azo-pyridine (1) and silver(I)-BINAP 2:1-catalyst. This catalytic process could be one of the effective synthetic routes to a number of chiral 1,4-diamines which are pharmaceutically important compounds. Further studies of the detailed mechanism of the reaction and synthetic applications are currently underway in our laboratory.

\section{Supplementary Material}

Refer to Web version on PubMed Central for supplementary material.

\section{Acknowledgements}

Support of this research was provided by National Institutes of Health (NIH) Grant No. GM068433-01 and Merck Research Laboratories. We thank Dr. Ian M. Steel for X-ray crystallographic analysis.

\section{References}

1. For a general review of hetero-Diels-Alder reactions, see: (a)FringuelliFTaticchiAThe Diels-Alder Reaction: Selected Practical MethodsJohn Wiley \& Sons2002(b)

KobayashiSJørgensenKACycloaddition Reactions in Organic SynthesisWileyVCHWeinheim20021509(c)JacobsenENPfaltzAYamamotoHComprehensive Asymmetric Catalysis IIISpringerBerlin1999123254 (d) Gouverneur V, Reiter M. Chem Eur J 2005;11:5806. (e) Jørgensen KA. Angew Chem Int Ed 2000;39:3558. (f) Tietze LF, Kettschau G. Top Curr Chem 1997;189:1.

2. (a) Yamamoto Y, Yamamoto H. Eur J Org Chem 2006:2031. (b) Yamamoto Y, Yamamoto H. Angew Chem Int Ed 2005;44:7082.Angew Chem 2005;117:7244. (c) Yamamoto Y, Yamamoto H. J Am Chem Soc 2004;126:4128. [PubMed: 15053601]

3. (a) Chowdari NS, Ahmad M, Albertshofer K, Tanaka F, Barbas CF III. Org Lett 2006;8:2839. [PubMed: 16774270] (b) Reetz MT. Chem Rev 1999;99:1121. [PubMed: 11749442] (c) Patel M, Kaltenbach RF III, Nugiel DA, McHugh RJ Jr, Jadhav PK, Bacheler LT, Cordova BC, Klabe RM, Erickson -VS, Garber S, Reid C, Seitz SP. Bioorg Med Chem Lett 1998;8:1077. [PubMed: 9871711] (d) Reedijk J. Chem Commun 1996:801. (e) Konradi AW, Pedersen SF. J Org Chem 1992;57:28. (f) Cummins CC, Beachy MD, Schrock RR, Vale MG, Sankaran V, Cohen RE. Chem Mater 1991;3:1153.

4. (a) Izawa K, Onishi T. Chem Rev 2006;106:2811. [PubMed: 16836300] (b) Specker E, Böttcher J, Brass S, Heine A, Lilie H, Schoop A, Müller G, Griebenow N, Klebe G. Chem Med Chem 2006;1:106. [PubMed: 16892342] (c) Engstrom K, Henry R, Hollis LS, Kotecki B, Marsden I, Pu Y-M, Wagaw S, Wang W. J Org Chem 2006;71:5369. [PubMed: 16808529] (d) Yeung CM, Klein LL, Flentge CA, Randolph JT, Zhao C, Sun M, Dekhtyar T, Stoll VS, Kempf DJ. Bioorg Med Chem Lett 2005;15:2275. 
[PubMed: 15837308] (e) Ikunaka M. Chem Eur J 2003;9:378. (f) Abdel RHM, Al KGS, El KNA, Youssef AF, Kiso Y. Curr Med Chem 2002;9:1905. [PubMed: 12369875] (g) Ghosh AK, Bilcer G, Schiltz G. Synthesis 2001:2203. (h) Kempf DJ, et al. J Med Chem 1998;41:602. [PubMed: 9484509] (i) Ettmayer P, Hübner M, Gstach H. Tetrahedron Lett 1994;35:3901. (j) Kempf DJ, Codacovi L, Wang XC, Kohlbrenner WE, Wideburg NE, Saldivar A, Vasavanonda S, Marsh KC, Bryant P, Sham HL, Green BE, Betebenner DA, Erickson J, Norbeck DW. J Med Chem 1993;36:320. [PubMed: 8426362]

5. (a) Robiette R, Cheboub BK, Peeters D, Marchand BJ. J Org Chem 2003;68:9809. [PubMed: 14656111] (b) Adam W, Bosio SG, Degen H-G, Krebs O, Stalke D, Schumacher D. Eur J Org Chem 2002:3944. (c) Urabe H, Kusaka K, Suzuki D, Sato F. Tetrahedron Lett 2002;43:285. (d) Zhang A, Kan Y, Jiang B. Tetrahedron 2001;57:2305. (e) Kaname M, Arakawa Y, Yoshifuji S. Tetrahedron Lett 2001;42:2713. (f) Dussault PH, Han Q, Sloss DG, Symonsbergen DJ. Tetrahedron 1999;55:11437. (g) Wyatt PB, Villalonga BC, Motevalli M. Tetrahedron Lett 1999;40:149. (h) Aspinall IH, Cowley PM, Mitchell G, Raynor CM, Stoodley RJ. J Chem Soc Perkin Trans 1 1999:2591. (i) Virgili M, Moyano A, Pericas MA, Riera A. Tetrahedron 1999;55:3959. (j) Aspinall IH, Cowley PM, Mitchell G, Stoodley RJ. J Chem Soc, Chem Commun 1993:1179.

6. Aburel PS, Zhuang W, Hazell RG, Jørgensen KA. Org Biomol Chem 2005;3:2344. [PubMed: 16010370]

7. Synthesis of similar compounds, see: Srinivasan V, Jebaratnam DJ, Budil DE. J Org Chem 1999;64:5644. [PubMed: 11674634]

8. The reaction of 2-triisopropylsilyloxy-1,3-cyclohexadiene with $\mathrm{CuPF}_{6}\left(\mathrm{CH}_{3} \mathrm{CN}\right)_{4}$ and $(R)$-BINAP gave the corresponding adduct with $>99 \%$ ee. The origin of this result is being investigated in our laboratory.

9. Reactions using the following metal catalysts were checked on TLC; Al, B, Mg, Zn, Ti, Sc, Hf, Yb, $\mathrm{Zr}$, In, La. None of them accelerated the reaction.

10. Momiyama N, Yamamoto H. J Am Chem Soc 2004;126:5360. [PubMed: 15113198]

11. Synthesis of silyloxydienes, see: (a) Nakashima D, Yamamoto H. J Am Chem Soc 2006;128:9626. [PubMed: 16866505] (b) Yamamoto Y, Yamamoto H. Angew Chem Int Ed 2005;44:7082.

12. Excess amount of AcOH was necessary to avoid epimerization of methyl group via retro-Michael reaction.

13. $\mathrm{SmI}_{2}$ mediated cleavage of N-N bond with trifluoroacetyl group, see: (a) Chowdari NS, Barbas CF III. Org Lett 2005;7:867. [PubMed: 15727461] (b) Ding H, Friestad GK. Org Lett 2004;6:637. [PubMed: 14961642] 


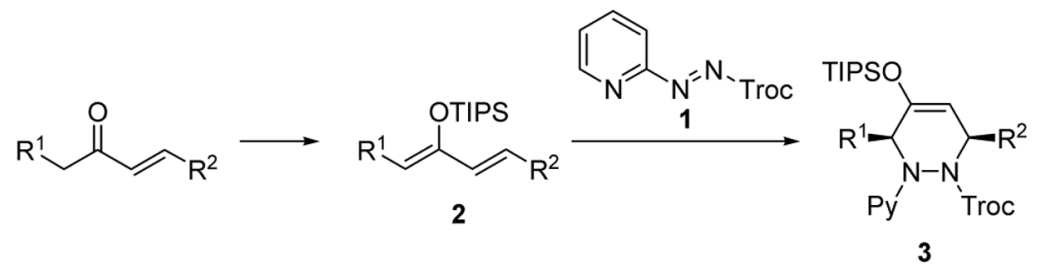

Scheme 1.

Azo hetero-Diels-Alder Reaction 


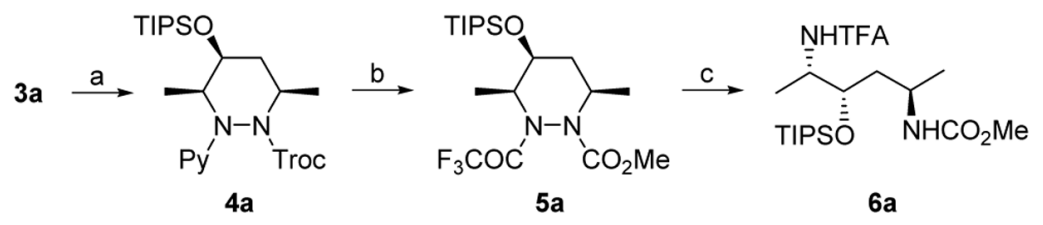

Scheme 2. Conversion to Protected Diamino Alcohol ${ }^{a}$

a (a) (i) TBAF, AcOH, (ii) $\mathrm{NaBH}_{4}$, (iii) TIPSOTf, $\mathrm{NEt}_{3}, 65 \%$ (3 steps); (b) (i) MeOTf (ii) $\mathrm{NaOH}$, (iii) TFAA, $\mathrm{NEt}_{3}, 71 \%$ (3 steps); (c) $\mathrm{SmI}_{2}, \mathrm{MeOH}, 71 \%$. 


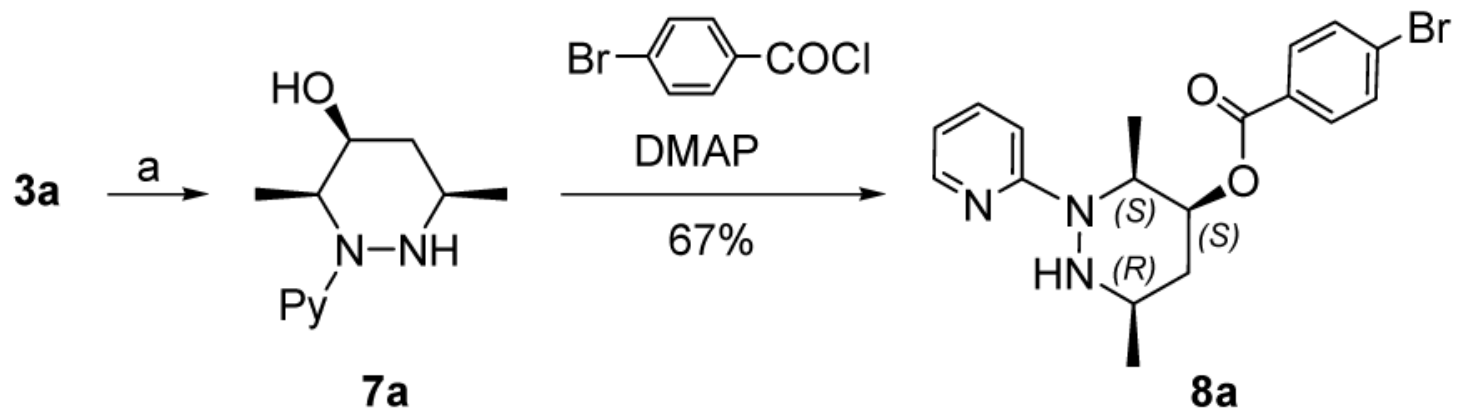

Scheme 3. Determination of Absolute Stereochemistry ${ }^{a}$

a (a) (i) $\mathrm{Zn}, \mathrm{AcOH}$, (ii) TBAF, $\mathrm{AcOH}$, (iii) $\mathrm{NaBH}_{4}, 53 \%$ (3 steps). 
Table 1

Optimization of Reaction Conditions

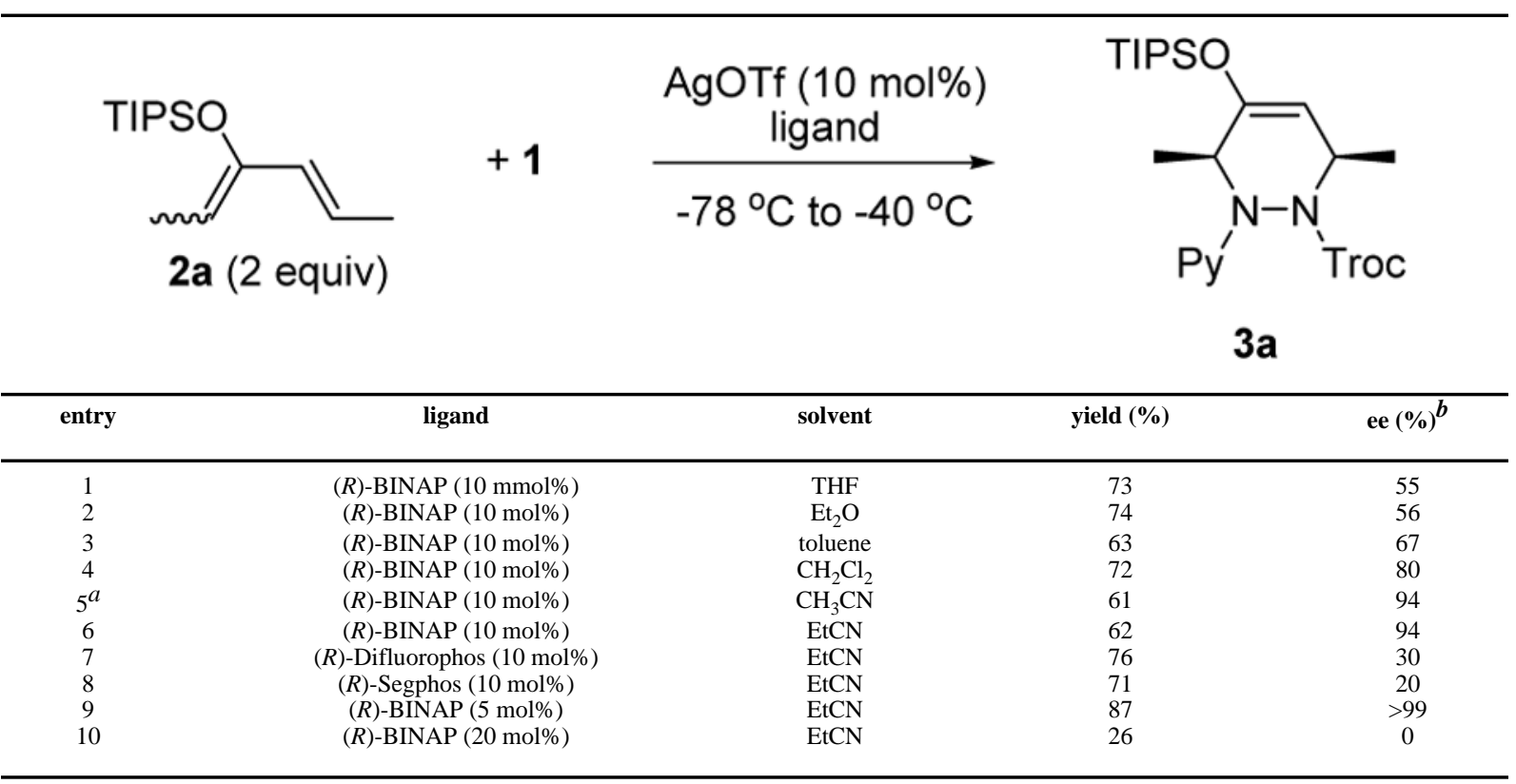

\footnotetext{
${ }^{a}$ Reaction was conducted at $-40^{\circ} \mathrm{C}$.

$b$ ee value was determined by HPLC (Supporting Information).
} 


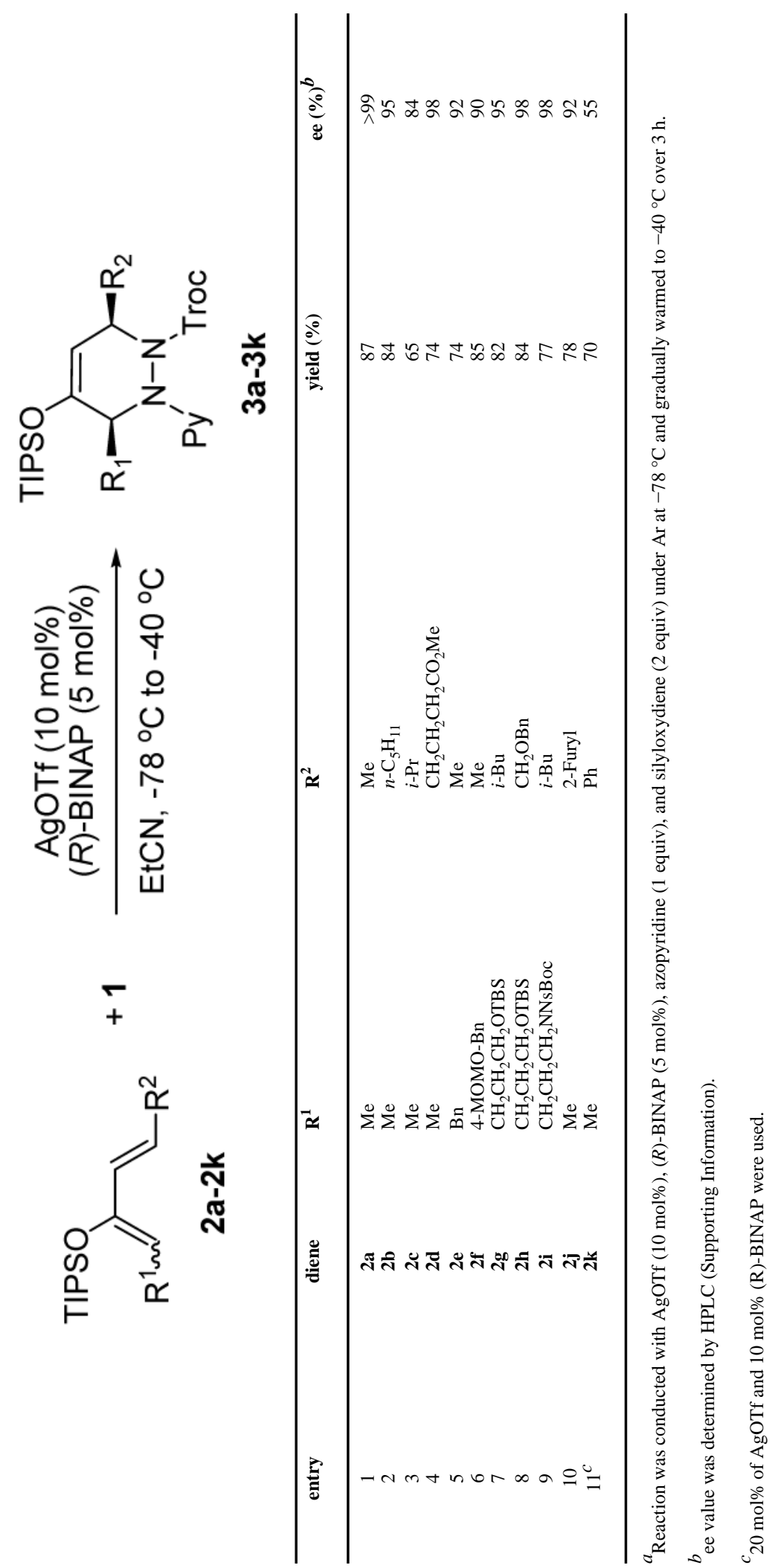

